Palabra Clave (La Plata)

ISSN: 1853-9912

palabraclave@fahce.unlp.edu.ar

Universidad Nacional de La Plata

Argentina

\title{
Las bibliotecas y las muestras digitales. Un análisis de los desarrollos actuales
}

Planas, Javier Armando; Kaplan Corti, Martina

Las bibliotecas y las muestras digitales. Un análisis de los desarrollos actuales

Palabra Clave (La Plata), vol. 9, núm. 2, 2020

Universidad Nacional de La Plata, Argentina

Disponible en: http://www.redalyc.org/articulo.oa?id=350562513006

DOI: https://doi.org/10.24215/18539912e093

Esta obra está bajo una Licencia Creative Commons Atribución-NoComercial-Compartirlgual 4.0 Internacional. 


\title{
Las bibliotecas y las muestras digitales. Un análisis de los desarrollos actuales
}

\author{
Javier Armando Planas \\ Biblioteca Nacional Mariano Moreno / Instituto de \\ Investigaciones en Humanidades y Ciencias Sociales \\ (UNLP-CONICET). Facultad de Humanidades y \\ Ciencias de la Educación (FaHCE). Universidad Nacional \\ de La Plata (UNLP), Argentina \\ jplanas@fahce.unlp.edu.ar \\ Martina Kaplan Corti \\ Biblioteca Nacional Mariano Moreno, Argentina \\ mar.kaplancorti@gmail.com
}

The library and the digital exhibition. An analysis of current developments.

DOI: https://doi.org/10.24215/18539912e093

Redalyc: http://www.redalyc.org/articulo.oa? id $=350562513006$

Recepción: 30 Octubre 2019

Aprobación: 28 Diciembre 2019

\section{Resumen:}

Como parte de un proyecto institucional radicado en la Biblioteca Nacional "Mariano Moreno" (Argentina), se presenta un análisis de diferentes exposiciones digitales de distintas bibliotecas del mundo. A partir de la bibliografía académica, se exponen algunas consideraciones sobre la cuestión. En la metodología se ofrecen los criterios de selección de la muestra y los principales aspectos estudiados: modalidad de acceso a los sitios webs, organización del contenido y características cuantitativas y cualitativas de las muestras digitales. Entre otros resultados, se observa que la información es sistematizada a través de diferentes ejes temáticos, dentro de los cuales se disponen las galerías de imágenes, los textos explicativos y los recursos audiovisuales. Asimismo, se constata que las bibliotecas que muestran tener una política en la materia obtienen los mejores productos curatoriales.

Palabras Clave: Muestras digitales, Exposiciones bibliográficas, Bibliotecas públicas, Bibliotecas nacionales, Argentina.

\section{Abstract:}

An analysis of different digital exhibitions of libraries is presented as part of an institutional project of the National Library "Mariano Moreno" (Argentina). From the academic bibliography, considerations on the matter are presented. In the methodology, the sample selection criteria and the main aspects studied are offered: access modality to the websites, organization of the content and quantitative and qualitative characteristics of the digital samples. Among the main results, it is observed that the information is systematized through different thematic axes, within which the image galleries, explanatory texts and audiovisual resources are arranged. Likewise, it is verified that the libraries that show having a policy in the matter obtains the best curatorial results.

KEYWORDS: Digital exhibition, Library exhibition, Public library, National library, Argentina.

\section{INTRODUCCIÓN}

El presente artículo se inscribe en el marco de un proyecto institucional radicado en la Biblioteca Nacional "Mariano Moreno" (BNMM) durante 2019, vinculado con el desarrollo de un sitio web para muestras bibliográficas digitales. Con este objetivo general, se trazó un plan trabajo con dos etapas definidas. La primera fue de diagnóstico, dentro de la cual se procuró analizar las producciones que en esta materia llevan adelante distintas bibliotecas de diversas partes del mundo y de similares características a la BNMM (en cuanto a fondos documentales, envergadura de la institución, públicos, etc.). La segunda fue de puesta a punto, de ensayo y error, y exigió la coordinación de equipos de trabajos formados por distintas áreas 
(Investigaciones, Diseño, Sistemas, Comunicación, Publicaciones), cada una con funciones específicas al momento de intervenir en la elaboración del proyecto.

En cuanto a la segunda etapa - y mientras se elaboran los documentos propios de este proceso, como la descripción detallada de la experiencia y los manuales técnicos y de procedimiento-, en noviembre de 2019 se inauguró en el sitio web de la BNMM un espacio específico para muestras digitales (http://exposiciones. bn.gov.ar/), con la presentación de dos exposiciones: A Todo Paturuzú y La experiencia cubana. Intelectuales argentinos en la revolución. En los criterios de elección de estas propuestas primaron dos razones: por un lado, se trataba de muestras que ya habían sido montadas en las salas de la BNMM y que contaban con catálogo de exposición, por lo tanto, la mayor parte del material gráfico y textual se encontraba procesado al momento de iniciar su conversión en formato digital, lo que redujo la tarea al análisis y la resolución de su disposición sistemática. Por otro, los contenidos de las muestras encarnaban dos planteos diferentes, uno relacionado con la trayectoria de la historieta en Argentina — representada por uno de sus personajes más emblemáticos -, el otro vinculado con la historia política e intelectual de nuestro país y de América Latina. Con todo, la apuesta fue amplificar el potencial público del sitio.

La conclusión de la primera etapa de trabajo se presenta a continuación, mediante una síntesis de la exploración del campo, la elaboración de una metodología de producción de datos, la exposición de los resultados del análisis y, por último, la elaboración de un balance global.

\section{CONSIDERACIONES GENERALES}

La idea según la cual las bibliotecas privilegian el acceso a sus colecciones sobre las funciones de conservación data del final del siglo XVIII, conforme se operó un cambio conceptual global en los modos en que los lectores y las lectoras se relacionaron con los libros (Lyons, 2012). Entre las consecuencias fácticas que esta inflexión tuvo para las bibliotecas cabría considerar, por ejemplo, la aparición del préstamo domiciliario de libros en el siglo XIX y, también, la formación de distintas estrategias para atraer lectores, como las veladas literarias y musicales, las conferencias de ocasión, la organización de talleres de artes y oficios, la proyección de ciclos de cine y el armado de muestras bibliográficas. A partir de 1920 este último tipo de actividades se acentuó conforme creció la competencia por el uso del tiempo libre de las personas, donde las bibliotecas de carácter público o popular tuvieron que competir con las propuestas del mercado.

Para las bibliotecas de fondos históricos, cuyo público mayoritario se caracterizó durante mucho tiempo por mantener una relación exclusivamente profesional con las colecciones, ese proceso de apertura progresiva y de exploración de actividades alternativas a las tradicionalmente ofrecidas fue mucho más lento que en otros tipos de establecimientos (Barbier, 2015). No obstante, las exposiciones bibliográficas como forma de presentar el patrimonio cuentan con una dilatada tradición. Una tradición que se modificó, también, con relación a dos series de transformaciones: de un lado, las que atañen al público, que de manera progresiva demandó productos curatoriales de mayores niveles de complejidad conceptual, gráfico y de montaje, es decir, una jerarquización de las funciones de curaduría o comisariado; de otro, las vinculadas con las modificaciones bibliotecológicas asociadas a las grandes bibliotecas que, sin dejar de atender las demandas habituales de los lectores, procuraron inscribir su presencia en sectores más amplios de la sociedad y, con ello, justificar también sus presupuestos.

En esta doble encrucijada, las bibliotecas nacionales y otras de fondos patrimoniales de importancia comenzaron a desarrollar toda una agenda de exposiciones permanentes y temporales y, al hacerlo, crearon también un sistema de memorias, en tanto que cada una de las muestras supuso la cristalización de una narración que sostuviera y significara los objetos bibliográficos seleccionados. Se trata, después de todo, de la conformación de contenidos con cualidad expositiva. Esta renovada manera de hacer circular el patrimonio institucional en la agenda pública requirió un esfuerzo organizativo, medible en términos de recursos humanos, estructurales, materiales y logísticos (como la incorporación de profesionales con diversas 
experticias, la radicación de nuevas áreas y funciones, la elaboración de redes institucionales de colaboración, etc.).

La expansión de Internet a mitad de la década de 1990 supuso, como se sabe, una progresiva transformación de la cultura del libro y, en consecuencia, de las formas de conducir las bibliotecas. Las exhibiciones bibliográficas no quedaron exentas. Ya en 2002 un trabajo publicado en El profesional de la información registró unas 71 exposiciones virtuales, considerando solo aquellas dedicadas al libro antiguo (Herrera Morillas, 2002). Entre las principales conclusiones, el autor subrayó, primero, que la nueva modalidad funcionaba, al menos en la mitad de los casos, como complemento de las muestras presenciales. En segunda instancia, que las grandes bibliotecas (Library of Congress, Bibliothèque Nationale de France y British Library) habían incorporado a sus sitios web un espacio exclusivo a estos efectos. En tercer lugar, que la nominación empleada usualmente era "exposición virtual". Finalmente, constató que la elaboración de los catálogos tradicionales se sostenía, y que su utilidad no había decaído.

Muchas de esas comprobaciones presentes en aquel artículo y los dilemas derivados de ellas aún se sostienen, con dos diferencias aparentes: la multiplicación exponencial de las propuestas y las más sofisticadas tecnologías con las que se cuentan en la actualidad para concretar las realizaciones. En este sentido, algunos especialistas sostienen que el efecto de superficie generado por los más avanzados diseños y las posibilidades de interacción no debe distraer del fondo del asunto, esto es: la capacidad de construir objetos expositivos, seleccionar con criterio el material y brindar un relato que lo signifique (Peñalver Gómez, 2017). De manera que, si bien las exposiciones en línea han abaratado ostensiblemente los costos de producción para las bibliotecas y de traslado para el público, el esfuerzo curatorial mantiene toda su vigencia (Lester, 2006). La permanencia del juego de complementariedad entre lo presencial y lo digital que ya se observaba al iniciarse la década de 2000 obedece, entonces, al intento por parte de las instituciones de maximizar el producto de su trabajo.

El relevamiento de sitios web de bibliotecas nacionales, públicas y universitarias producido para este artículo confirma el fenómeno detallado de forma precedente (ver Anexo 1), así como también los tipos elementales de relaciones que se extienden en la actualidad entre lo digital y lo presencial, que fueron descritos de manera temprana por José Luis Herrera Morillas (2005). El autor distinguió tres modelos globales de complementariedad: 1) de difusión, cuyo objetivo es amplificar la convocatoria de la muestra presencial mediante la presentación en línea de una parte ínfima de esta; 2) de conexión, a través de la cual lo digital sirve como mecanismo de expansión de contenidos; 3) de superposición, donde se presenta una yuxtaposición de tópicos entre un contexto expositivo y otro. A estos tres modelos, cabría consignar una cuarta instancia de relación, definida como la virtualidad de lo presencial, es decir, la progresiva incorporación de herramientas tecnológicas en las salas. En este contexto, se distinguen con claridad dos recursos: por un lado, el empleo de pantallas táctiles que suplantan al objeto real y, por otro, el uso de instancias interactivas facilitadas por las conexiones a Internet que posibilitan los dispositivos móviles, y que abarcan un abanico de opciones muy variado, como visitas guiadas, musicalizaciones pensadas para determinados espacios de las salas, ampliaciones bibliográficas, etc. En 2014, La Casa de Lector de Madrid presentó, conjuntamente con la Biblioteca Nacional de Israel, una exposición virtual con estas características (Fundación Germán Sánchez Ruipérez, 2015). Si bien la reseña del diario El País (Contenla, 6 de marzo del 2014) la identificó como "solo virtual", lo cierto es que el público debía desplazarse hasta la Casa del Lector y allí, en una de las salas preparadas al efecto, accedía mediante códigos QR a los objetos bibliográficos y a las infografías, organizadas en este caso con el software The Brain (https://www.thebrain.com/), una herramienta para elaborar mapas conceptuales. Un tipo de iniciativa diferente - pero consistente con esta modalidad de incorporación tecnológica-, lo presentan las bibliotecas que buscan suplantar, en las salas de lectura, las tradicionales vitrinas de novedades o de pequeñas exposiciones con pantallas dispuestas al efecto (Ajmi, 2014). Con todo, se trata de una forma más de mediatizar el espacio. 
De forma paralela a las experiencias que entrecruzan lo presencial y lo digital, las bibliotecas también desarrollaron exhibiciones puramente virtuales. A las ya mencionadas ventajas de los costos de producción que esta variante supone para la institución, cabe consignar otra no menos significativa: el alcance potencial de público. La web ciertamente recorta tiempo y distancia, un valor apreciado entre las bibliotecas cuyos fondos y finalidades están asociadas a las delimitaciones constituidas por los estados-nación. Esta opción, asimismo, fue ponderada positivamente por algunos especialistas en términos de oportunidades para desarrollar una política institucional de exhibiciones de forma independiente y diferenciada de las muestras presenciales (Saorín, 2011). En este contexto, la elección de la plataforma web a utilizar supone una serie de dilemas, dado que, como en toda puesta en escena, la forma condiciona los sentidos. Principalmente, se trata de resolver la tensión entre la armonía global del sitio, que permite cierta estabilidad y coherencia, y los desarrollos que cada proyecto curatorial exige, donde los contenidos y el modo de exhibirlos requieren un tratamiento específico. Mientras algunas bibliotecas han optado por desarrollos propios, otras adoptaron diseñados prestablecidos, como el software Omeka (https://omeka.org/)(Alcaraz Martínez, 2012) o las herramientas que ofrece Goolge Open Gallery (https://artsandculture.google.com/opengalleryinfo).

\section{Metodología}

A los efectos de evaluar propuestas de exposiciones bibliográficas digitales, se procedió a realizar un relevamiento con criterios específicos de selección:

1. Que las muestras bibliográficas pertenezcan a bibliotecas que se caractericen por disponer de fondos históricos, principalmente las Nacionales, pero también algunas universitarias y públicas.

2. Que estas instituciones dispongan de un espacio fijo en la página denominado "exposiciones virtuales" (o similares).

3. Que estos espacios no constituyan, en sí mismos, repositorios digitales a texto completo o simples galerías de imágenes.

4. El área de cobertura ocupa: América Latina, América del Norte y algunos países centrales de Europa.

5. Período de búsqueda: 14 de enero al 28 de enero de 2019.

Sobre la base de los criterios precedentes, se escogieron los sitios de muestras digitales de 15 bibliotecas de diferentes países. En conjunto, los casos seleccionados saturan metodológicamente las variantes de contenido y los diseños posibles, es decir, ningún sitio que se incorpore al grupo agrega información significativamente novedosa.

En el contexto de América Latina se privilegió la búsqueda de bibliotecas nacionales. Los resultados fueron escasos: solo se encontraron 4 sitios de interés potencial: Biblioteca Nacional de Brasil, Biblioteca Nacional de Perú, Biblioteca Nacional de Colombia, Biblioteca Nacional de Cuba. Entre las bibliotecas de América del Norte, se seleccionaron tres de Estados Unidos: Library of

Congress, New York Public Library, Harvard University. Finalmente, entre las instituciones de Europa se escogieron: tres de Inglaterra: British Library, Cambridge University, Oxford University; dos de España: Biblioteca Nacional de España, Biblioteca de la Universidad de Sevilla; una de los siguientes países: Francia: Bibliothèque Nationale de France; Alemania: Staatsbibliothek zu Berlín; Irlanda: National Library of Ireland; Italia: Biblioteca Nazionale Centrale di Roma.

De los sitios precedentes, se tomó al menos una exposición de cada uno de ellos para conformar una muestra. Inicialmente, los puntos de análisis fueron los siguientes:

1. Página principal del sitio web de muestras: créditos generales del área; distinción entre muestras solo virtuales y complementarias; muestras actuales/pasadas. 
2. Página de muestra:

2. 1. Estructura general: forma del recorrido (scroll, ejes temáticos); niveles de profundidad; formas de ir y volver al contenido.

2.2. Información general: institución responsable; créditos; contacto; fecha de inauguración/presentación; vinculación con una muestra presencial.

2.3. Información curatorial: portada; textos para cada eje; epígrafes de las imágenes; cantidad de imágenes; cantidad de videos; disposición de galería de imágenes; líneas de tiempo, mapas conceptuales y otras infografías; objetos bibliográficos digitales.

A partir de los principios enunciados, los resultados del análisis se disponen en tres segmentos generales: acceso, organización del contenido y características del contenido.

\section{Resultados}

\section{1. El acceso}

Durante la primera fase del análisis se estudiaron las páginas de inicio. Se consideró, en primer término, el camino que deben recorrer los usuarios hasta dar con el sitio que agrupa las muestras virtuales y, en segundo, la información que contiene y cómo está ordenada. En general, puedeobservarse que desde la página inicial hasta el espacio de las muestras en cuestión no hay más de tres clicks de distancia y, en la mayoría de los casos, solo dos. Asimismo, se detecta que términos como "eventos", "exhibiciones" y "actividades" (en las variantes idiomáticas correspondientes) funcionan como las etiquetas más habituales dentro de los menús principales para incluir, en el contexto de la oferta cultural de la institución, el acceso a las muestras. Cabe consignar, también, que la nominación de estos sitios no tiene muchas variantes entre los casos analizados: se prefieren, por lo regular, los sustantivos "exposiciones" o "exhibiciones" acompañados por los adjetivos "virtuales" u "on-line", lo que expresa una continuidad respecto de lo constatado por los estudios pioneros en la materia (Herrera Morillas, 2002). Esto significa, entonces, que las bibliotecas han optado por distinguir estas propuestas de aquellas que son solo presenciales. Pero esta diferenciación no siempre es clara, puesto que muchas de las muestras digitales guardan algún tipo de relación de complementariedad con las exposiciones presenciales (tal como se observó en el primer apartado). A los efectos de la presentación, pocas bibliotecas informan de manera visible esta situación. Cambridge University Library es un ejemplo de buena práctica, puesto que ofrece al usuario el modo de visita posible y disponible, con fecha de cierre en el caso de las exposiciones in situ.

Los sitios de las muestras on-line reportan tantas diferencias como las que hay entre las plataformas empleadas por las bibliotecas. No obstante, hay una línea de continuidad que puede descubrirse al fijar la atención en el modo de presentar las propuestas: cada una de las muestras se anuncia mediante lo que habitualmente se conoce como portada de la exposición, y que está compuesta por una imagen alusiva y el título. Esta distinción estética es acompañada, en la mayoría de los casos, por una nota de alcance que especifica los contenidos que el usuario puede esperar o encontrar. Generalmente, esta información se dispone en el centro de la página una debajo de la otra, de forma tal que se privilegian las novedades y, al mismo tiempo, se forma un historial con las exposiciones pasadas. Algunas instituciones, como la Bibliothèque Nationale de France, emplea una galería en la parte superior del sitio para las muestras en curso y, debajo, aquellas que forman parte del archivo. Las herramientas de búsqueda, cuando las hay, se limitan al buscador estándar del propio sitio. La British Library se destaca por disponer un filtro de búsqueda temático y otro temporal, además de ofrecer la posibilidad de ordenar la serie de muestras por orden cronológico y alfabético, 
en sentido ascendente y descendente (Figura 1: https://www.bl.uk/discover-and-learn/online-exhibitions $\#$ ).

\section{FIGURA 1}

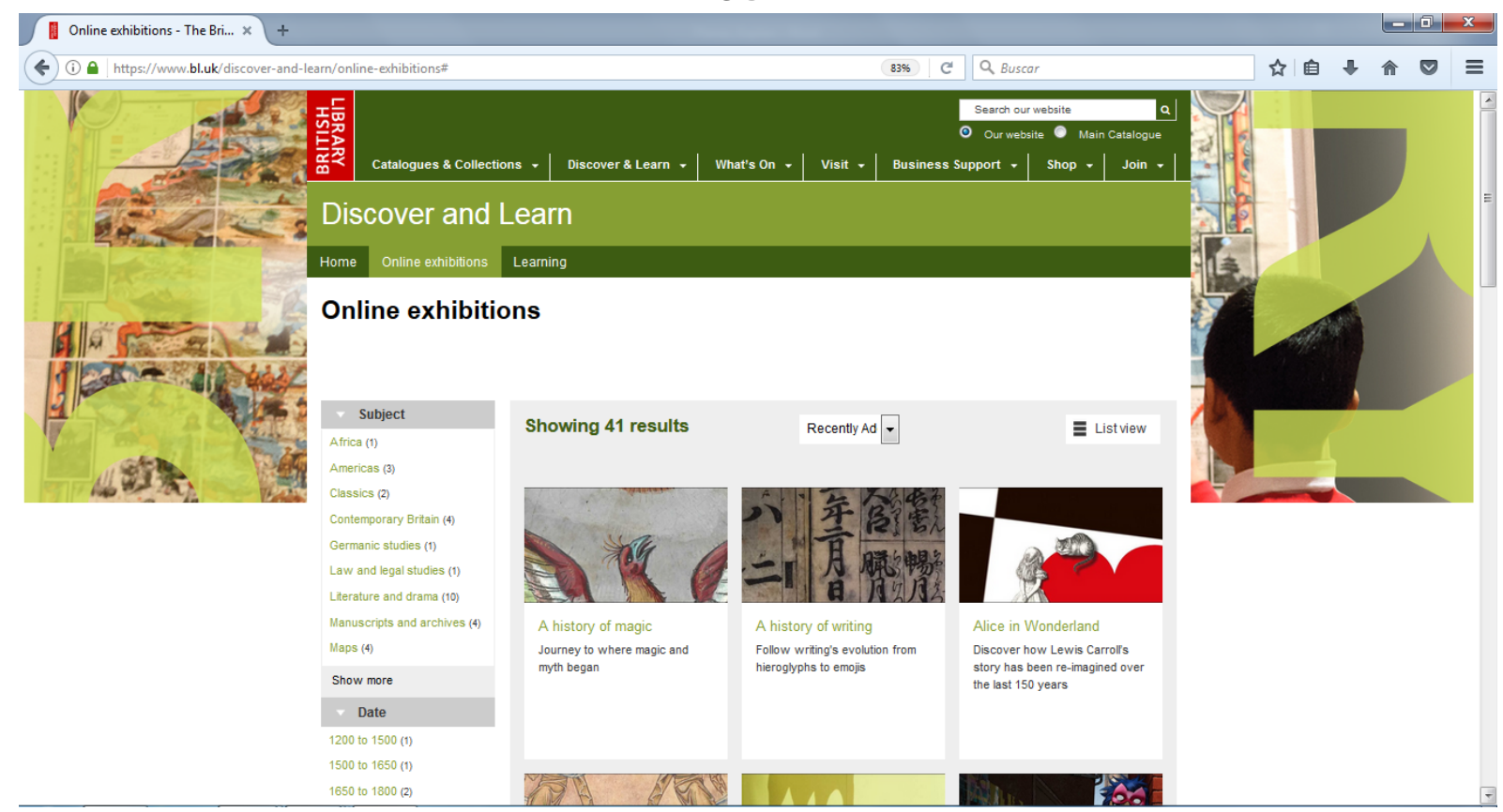

Finalmente, y en cuanto a cierta información complementaria, son muy pocas bibliotecas las que ofrecen alguna línea referida al propósito de las muestras on-line, a los responsables de administrar las propuestas o a los aspectos técnicos de la plataforma empleada a estos efectos. Contrariamente, la mayoría de las instituciones disponen vías de contacto para los usuarios: dirección de correo electrónico, redes sociales y, en menor medida, teléfono y dirección postal.

\subsection{Organización del contenido}

En la segunda parte del análisis la atención se focalizó en las muestras propiamente dichas. Por un lado, se estudiaron los rasgos generales de la organización del contenido y las formas de navegación o desplazamiento interno; por otro, se observaron las características y la disposición de la información textual, visual y audiovisual.

En relación al primer aspecto, se encontraron al menos cuatro modelos generales de presentación u organización del contenido, con mayores o menores niveles de complejidad y realización. El modelo 1, predominante en las exhibiciones recorridas, sigue una estructura semántica clásica, esto es: en el nivel inicial se despliega una portada, compuesta por lo regular por una imagen representativa, el título y, en algunos casos, un texto curatorial. Seguidamente, se presenta un sistema de ejes temáticos, conformados en casi todos los casos por una imagen y un título y, ocasionalmente, un texto orientativo. Se constató, asimismo, que se emplean entre tres y seis temas, dentro de los cuales se desarrolla el contenido, tangible en artículos, imágenes, videos y documentos completos. En cuanto al sistema de navegación interna las exposiciones suelen tener variaciones importantes. Una de las herramientas más utilizadas, y una de las que mejor funciona, es el menú fijo de opciones, mediante el cual el usuario puede adentrarse en los distintos ejes temáticos sin importar el nivel de profundidad y, a la vez, mantener siempre la perspectiva global y la posibilidad de volver al inicio o al nivel anterior sin recurrir al navegador. Un ejemplo satisfactorio de este modo de organización lo constituye la muestra Emile Zolá: Au Bonheur des dames (Figura 2). En la mayor parte de las exposiciones se requiere el uso 
del scroll para visualizar todos los contenidos, aunque existen diferencias de grado en este empleo: en algunos casos, como en Eine Bibliothek macht Geschichte, el recorrido es puramente vertical (con un inconveniente: el menú de ejes no es fijo), mientras que en otros, como la muestra dedicada a Zolá citada precedentemente, apenas necesita desplazamiento. Dentro de estos esquemas también se observan prácticas no aconsejables, como la ausencia de vínculos que permitan salir de un espacio a otro o ir directamente al inicio. En este caso, al igual que con los vínculos que abren a sitios completamente diferente en la misma pestaña (a youtube, por ejemplo), obligan al usuario a emplear el navegador para volver a situarse en el sitio de la muestra.

FIGURA 2

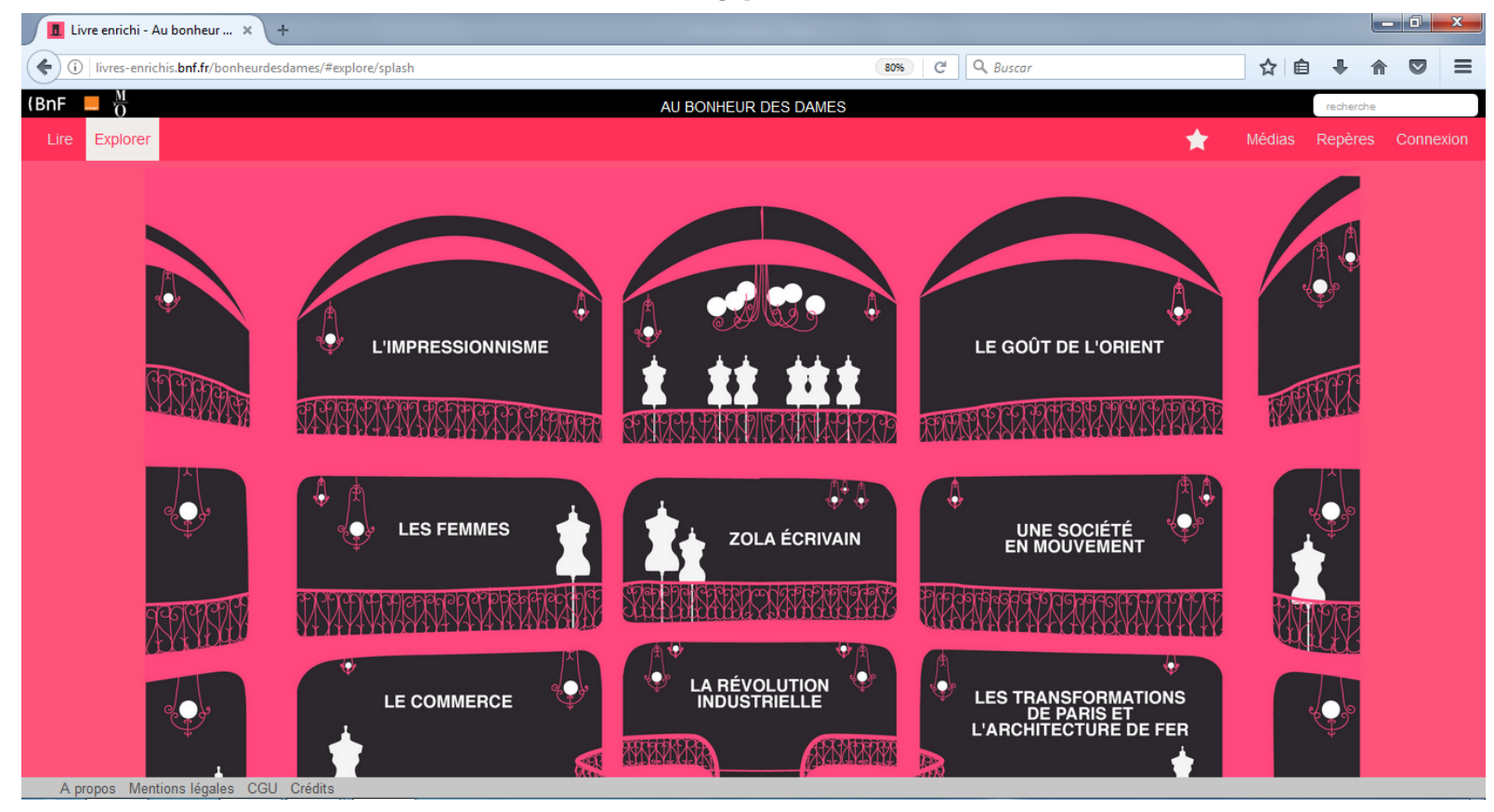

El modelo 2 organiza los contenidos a la manera de un catálogo de exposiciones tradicional. Se observan, no obstante, dos modalidades completamente diferentes de realización. La primera queda representada por la propuesta de la Biblioteca Nacional de España, que auspicia exposiciones virtuales derivadas de aquellas presenciales, y las ofrece a través de un libro navegable en un solo sentido y sin objetos digitales desplegables en pantalla o descargables, limitándose entonces a presentar imágenes de las salas y los textos explicativos. La muestra Cosmos es un ejemplo de esta descripción. En sentido estricto, el concepto de exposición virtual en este y en otros casos similares es, al menos, cuestionable. La segunda modalidad es por completo diferente. La muestra Alice in Wonderland una estructura de libro, en tanto que se desarrolla a través de artículos que cubren cada uno de los temas, pero el sistema de navegación y la posibilidad de explorar manuscritos (y sus respectivas transcripciones), galerías de imágenes y otros recursos la convierten en una auténtica exposición virtual.

El modelo 3 presenta un $360^{\circ}$. No es habitual el uso de este recurso, aunque es posible localizarlo en algunas instituciones. La biblioteca Nacional de Irlanda ofrece mediante este sistema una réplica virtual de su exposición presencial The Life and Works of William Butler Yeats (Reilly y Petrelli, 2007; Kail, 2010). En este ejemplo el usuario puede acercarse a cada una de las vitrinas y desplegar su contenido, ya se traten de imágenes, textos o audiovisuales (Figura 3). Muy diferentes son las exhibiciones de la Biblioteca Nacional de Perú, cuyo $360^{\circ}$ es un desarrollo exclusivamente digital, mediante un software de simulación de realidad. Más allá de la calidad gráfica deficiente de este programa en particular (que presenta dificultades para el desplazamiento interno, para la lectura de textos y la visualización de las imágenes), la propuesta resulta algo exigua, en tanto que se sujetan las posibilidades de lo digital a un modelo de sala espacial, sin necesidad de que tal cosa exista. En ambos casos, la navegación se hace a través del mouse y las flechas del teclado. 


\section{FIGURA 3}

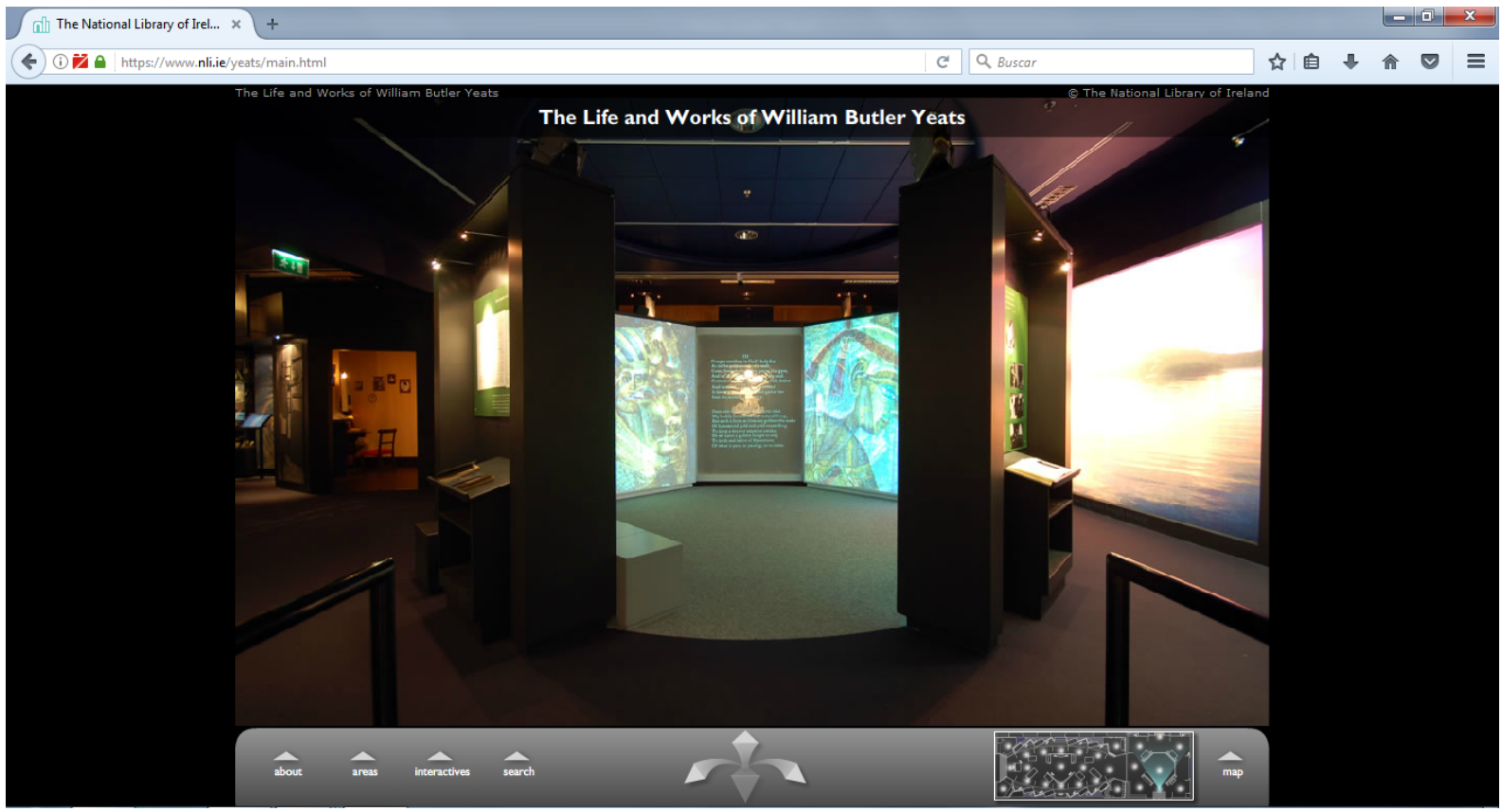

El modelo 4 es, en rigor, la propuesta conjunta entre la British Library y Google, en la plataforma de esta compañía: Harry Potter a History of Magic. La muestra tiene varias singularidades, pero interesa subrayar por sobre otras cuestiones su modo de organizar el contenido, que presenta herramientas combinadas de los modelos precedentes, sin guiar al usuario por un recorrido prestablecido. La estructura del sitio propicia, como ninguna otra exposición, un "picoteo" informativo. Prescindiendo de evaluaciones valorativas en relación con los planteos más tradicionales, ciertamente la ausencia de elementos de navegación prácticos dificulta moverse dentro del mismo sitio e, incluso, dejan al usuario con dudas acerca de si visitó o no de forma completa la muestra.

\subsection{Características del contenido}

Las características de la información textual, visual y audiovisual presentes en el conjunto de muestras observadas permite ubicar ciertas semejanzas generales de orden cuantitativo, aunque diferencias radicales según la calidad de la curaduría — por encima de las posibilidades técnicas de los sitios-. Respecto de lo primero, por ejemplo, el $61 \%$ de las exposiciones visitadas declara los créditos, es decir, manifiesta los nombres de los curadores y el equipo de trabajo que realizó la propuesta. Idéntico porcentaje se constata al revisar la presencia de la fecha de inauguración, que no casualmente coincide casi con exactitud cuando la muestra es un complemento digital de una exhibición presencial. Visto desde otro ángulo, son pocos los sitios de exposiciones enteramente digitales que explicitan la fecha de lanzamiento y/o vigencia. Por último, y dentro de lo que podemos considerar como información general, al menos una vía de contacto fue localizada en todos los sitios, aunque se registró una variación importante en cuanto a la cantidad de datos suministrados (dirección postal, teléfono, e-mail, redes sociales de distinto tipo).

En lo que respecta a la información propiamente dicha de las muestras, hay patrones que se mantienen desde la tradición física o presencial, como el uso de una imagen como marca (100\%) y el texto curatorial o introductorio de referencia (77\%). También es notable la coincidencia que se extiende entre lo que puede denominarse como información básica del contenido, esto es: textos explicativos de los ejes (77\%) y epígrafes de los documentos exhibidos (100\%). En cambio, las infografías clásicas, como las líneas de tiempo diacrónicas o sincrónicas son escasas. Se ofrece, al menos en la mitad de los casos analizados, otro tipo de 
información referencial, entre las que se destacan las bibliografías y las antologías. En párrafos anteriores quedó expresado que el modelo 1 de estructuración de contenido para las muestras digitales, por lo regular, emplea entre tres y seis ejes temáticos (quedó dicho, también, que los otros modelos son residuales). En cada uno de estos segmentos, suele presentarse un texto explicativo que promedia los 2.160 caracteres (sin espacio), con un máximo de 6.915 y un mínimo de 300, según el carácter de la muestra y si se trata de lo que comúnmente se reconoce como "texto de sala" o artículo completo. En cuanto a las imágenes por eje, se percibe una oscilación que va desde 1 a 30, con un promedio de 11. Entre los contenidos, el $85 \%$ de las muestras presentan algún tipo de objeto digital, considerados aquí como imágenes, manuscritos o impresos (completos o fragmentarios), que facilitan la ampliación en pantalla y/o la descarga. Un recurso mucho menos empleado es el video, que aparece solo en el $31 \%$ de los casos analizados.

Las expresiones cuantitativas precedentes no reflejan, sin embargo, las notables diferencias cualitativas en lo que respecta al proceso de curaduría y realización. En otras palabras, el uso de recursos semejantes no implica resultados similares. Dentro de aquello que se puede reconocer como buenas prácticas, la muestra Emile Zolá: Au Bonheur des dames presenta una labor de investigación realmente cuidada y de larga duración. El sitio se divide en dos grandes segmentos, uno que corresponde a la edición crítica de $A u$ Bonheur des dames (http://livres-enrichis.bnf.fr/bonheurdesdames/\#reader/0/1) (disponible además como audio, en la lectura de un reconocido actor francés); otro constituido por la exposición (http://livres-enrichis.bnf.fr/b onheurdesdames/\#explore/splash) propiamente dicha, que toma como punto de partida la obra y presenta sus relaciones con diferentes tópicos (el impresionismo, la revolución industrial, etc.). En cada eje, lo que se percibe a simple vista es un equilibrio entre la extensión de los textos y las imágenes. Hay, por ejemplo, un promedio de 25 ilustraciones por cada eje, dispuestas de tal modo que no satura la impresión visual del usuario ni le exige grandes esfuerzos de desplazamiento. Lo interesante es que este efecto no es el resultado de un sofisticado sistema técnico, sino de la concepción conceptual y estética. Contrariamente, una muestra como As mãos que restauram o tempo, auspiciada por la Biblioteca Nacional de Brasil, presenta una cantidad similar de imágenes por eje temático (http://bndigital.bn.gov.br/exposicoes/biblioteca-nacional-as-maos-q ue-restauram-o-tempo/a-obra/), pero en tamaño mayor y pegadas una debajo de la otra. De este modo, la percepción panorámica cede y el usuario debe invertir un tiempo considerable en recorrer el sitio con el scroll.

La calidad de una muestra también puede apreciarse mediante los diferentes segmentos de público que pueden disfrutarla y aprovecharla. En Alice in Wonderland el tema, la distinción estética, la calidad investigativa y el recurso informático se combinan de modo tal que dicho valor alcanza niveles altos de satisfacción. Solo basta con comparar, por ejemplo, una parte de la muestra en la que se ofrece el manuscrito Alice's Adventures Under Ground (https://www.bl.uk/works/alices-adventures-in-wonderland) acompañado de una trascripción página a página del texto, sin duda un atractivo para especialistas, con otros artículos de la exposición que remiten a colecciones de ilustraciones (https://www.bl.uk/collection-items /the-nursery-alice) del libro. Evidentemente, no todos los objetos expositivos permiten esta versatilidad y, también, es cierto que las tipologías de bibliotecas determinan sus públicos. Así, por ejemplo, Cambridge University Library concibe sus muestras digitales desde otras perspectivas. Pero, aun así, una propuesta como Revolution: the first Bolshevik Year puede ser apreciada por docentes y estudiantes de todas las carreras de la universidad sin perderse en el intento.

Otra dimensión a considerar, que indudablemente está asociada a la cantidad de contenidos (en sus diversas expresiones), refiere al tiempo global del recorrido. Por supuesto, como sucede en las exposiciones presenciales, existe un público que pasa por la muestra y otro que la transita o la habita. Esto significa que el tiempo de observación es relativo, y su determinación depende, por un lado, del interés del usuario y su conocimiento del tema; por otro -y tal como quedó dicho-, de la calidad gráfica de la exposición, el contenido que presenta, la organización conceptual y las formas de desplazamiento. Si la primera de estas variantes escapa al dominio de las bibliotecas, las otras tres pueden ser contraladas. Dos buenas muestras pueden ejemplificar la densidad temporal de las exposiciones digitales: Frankenstein: The Afterlife of Shelley's Circle, 
preparada por la New York Public Library, y Base Ball Americana, organizada por la Library of Congress. La primera presenta una estructura general de cuatro ejes, dentro de los cuales se encuentra una columna que contiene de siete a diez artículos sobre la cuestión, de unos 7.000 caracteres (sin espacio). Esto significa que solo de contenido textual hay que considerar una extensión de 90 páginas aproximadamente, sin contar los documentos e imágenes que en cada uno de estos ensayos se insertan. Este volumen de información es la mitad de la muestra, puesto que una segunda columna contiene entre otras cosas dos galerías de imágenes, con 17 ilustraciones en promedio, acompañadas por un breve texto explicativo general, y un epígrafe para cada una de ellas. Con todo, The Afterlife of Shelley's Circle es una muestra y un catálogo a la vez, agotar su contenido puede tomar varias jornadas completas y, sin embargo, aquellos que deseen leer un fragmento o recorre algunas de sus galerías también pueden llevarse una buena sensación, aunque a sabiendas de que han dejado mucho material por visitar. Por su parte, Base Ball Americana remite a una organización clásica: portada, introducción y cinco ejes temáticos, cada uno con un texto breve y tres o cuatro subtemas que, a la vez, son contenedores de un fragmento explicativo y siete documentos como contenido (Figura 4). De manera que, al considerar la dimensión temporal, la muestra puede transitarse de forma completa en un lapso relativamente acotado, puesto que el volumen informativo global es abarcable y, sin embargo, suficiente para que un usuario interesado en la temática pueda iniciar una búsqueda más ambiciosa por su propia cuenta.

\section{FIGURA 4}
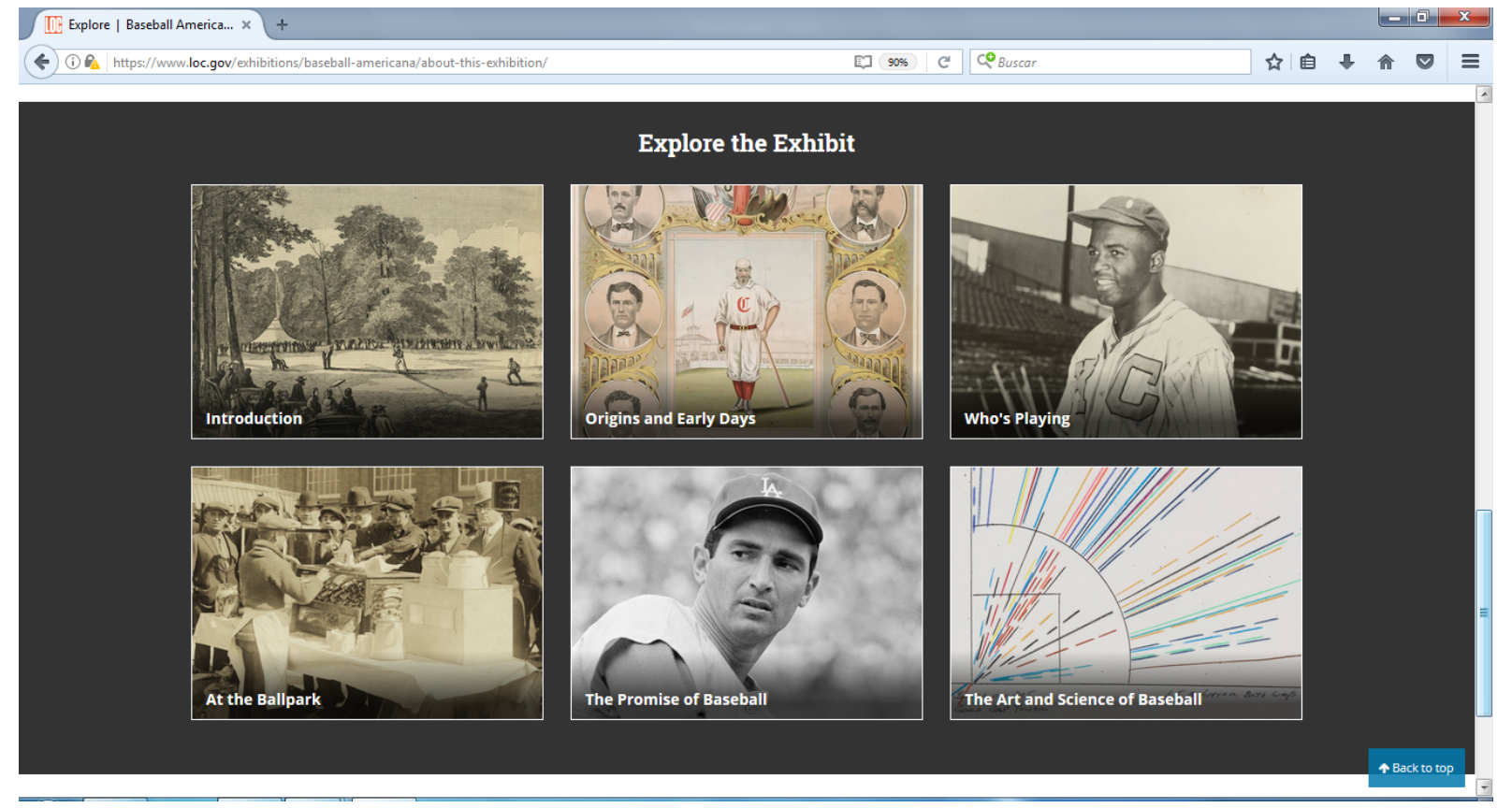

\section{A MODO DE CONCLUSIÓN}

Del recorrido presentado hasta aquí, se pueden extraer 3 conclusiones:

1. Para las bibliotecas, las muestras digitales suponen una transformación más en el contexto general de conversión digital a la que asisten estas instituciones desde hace décadas. Una conversión que, según se puede constatar a la fecha, no está relacionada con un reemplazo de lo presencial por lo virtual, sino con una extensión de lo primero sobre lo segundo. Como se observa en los resultados del análisis precedente, la mayor parte de las exposiciones bibliográficas digitales constituyen un producto derivado de las exhibiciones in situ. Esto sugiere que las bibliotecas procuran maximizar el alcance de sus propuestas culturales, al reconvertir la naturaleza inicial de estos proyectos para 
situarlos a disposición de un público potencialmente ilimitado en la web. Esta situación fue objeto de diferentes estudios críticos, dentro de los cuales se destaca una conclusión primordial: el esfuerzo curatorial que requiere elaborar una muestra bibliográfica de calidad, sea puramente digital u originada de una exposición presencial, conserva todo su sentido.

2. Al explorar los sitios de muestras digitales se constata la presencia de continuidades y divergencias entre los casos estudiados. Entre las primeras, es posible identificar un modelo de exposición predominante, que consiste en el empleo de estructuras semánticas jerarquizadas, dentro de las cuales se despliegan contenidos variables en imágenes, textos y audiovisuales. Las divergencias cualitativas se aprecian de forma considerable entre las organizaciones que disponen de una verdadera política de exposiciones digitales y aquellas que no. Esta cuestión, por supuesto, se verifica en la trayectoria que cada una tiene en la materia (tangible en el historial de muestras) y, en consecuencia, en los recursos técnicos y humanos disponibles. Esta experiencia institucional acumulada redunda en la calidad de las producciones, medible en términos claridad conceptual, elegancia del diseño, facilidad de acceso, navegabilidad, pluralidad de recursos, etc. En síntesis, las instituciones que dedican un esfuerzo sostenido alcanzan, antes o después, los mejores productos.

3. Las instituciones que busquen difundir sus fondos bibliográficos mediante iniciativas de este tipo deben estar dispuestas a realizar inversiones. En primer lugar, tiempo y recursos humanos para explorar y evaluar los sitios de muestras digitales de diferentes bibliotecas. Este artículo cumple con el objetivo de contribuir con ese paso inicial, además de facilitar un anexo con sitios web específicos. Sin embargo, cada institución debe fijar un horizonte entre lo deseable y lo factible, entre aquello que quisiera hacer y lo que efectivamente puede hacer. El conocimiento de esas variables facilita, entonces, la toma de decisiones sobre la elaboración de las propuestas. En segundo lugar, es fundamental no dejarse maravillar por los recursos informáticos que, si bien son parte central en la construcción de sentidos, resultan inocuos sin la mediación de una sólida construcción conceptual. El resultado de cada muestra digital es la suma de un equipo de trabajo en la que intervienen investigadores, bibliotecarios, diseñadores e informáticos, entre otros especialistas. Por esta misma razón, se requiere una articulación global de los esfuerzos para ubicar en un mismo rumbo la diversidad de propuestas temáticas que pueden desarrollar las bibliotecas.

\section{REFERENCIAS}

Ajmi, A. (2014), The DIY digital exhibition experience at Tarrant County College. Journal of library innovation, 5(1), 98-126. Recuperado de https://papers.ssrn.com/sol3/papers.cfm?abstract_id=2443592

Alcaraz Martínez, R. (2012). Omeka: exposiciones virtuales y distribución de colecciones Digitales. BiD: textos universitaris de biblioteconomía i documentaci, (28). Recuperado de http://bid.ub.edu/28/alcaraz2.htm

Barbier, F. (2015). Historia de las bibliotecas: de Alejandría a las bibliotecas virtuales. Buenos Aires: Ampersand.

Contenla, T. (6 de marzo del 2014). La memoria judía se expone en iPad. El País. Recuperado de https://elpais.com /cultura/2014/03/05/actualidad/1394047004_090821.html

Fundación Germán Sánchez Ruipérez. (13 de noviembre de 2015). Exposición virtual de la Biblioteca Nacional de Israel [Archivo de video]. Recuperado de https://www.youtube.com/watch?v=pZBSJlfa9C0

Herrera Morillas, J. L. (2002). Páginas web sobre exposiciones virtuales de fondo antiguo: recopilación y análisis. El profesional de la información, 11(2), 121-136.

Herrera Morillas, J. L. (2005). Las bibliotecas y las exposiciones virtuales: orientaciones para su diseño. Scire, 11(1), 113-122.

Kail, C. (2010) Ireland. Journal of web librarianship, 4(1), 87-95. DOI: https://10.1080/19322900903547257 
Lester, P. (2006) Is the virtual exhibition the natural successor to the physical? Journal of the Society of Archivists, 27(1), 85-101. DOI: https:// 10.1080/00039810600691304

Lyons, M. (2012). Historia de la lectura y de la escritura en el mundo occidental. Buenos Aires: Editoras del Calderón.

Peñalver Gómez, E. (2017) El libro antiguo: Los problemas para su difusión entre los lenguajes de musealización y la digitalización». RUIDERAe. Revista de unidades de información, 12, 91-108. Recuperado de https://revista.uc $\mathrm{lm} . e s /$ index.php/ruiderae/article/view/1618

Reilly, S. and Petrelli, D. (2007) Engaging with books you cannot touch: interactive multimedia to expose library treasures. CoDesign, 3(1), 199-210. DOI: https://10.1080/15710880701324521

Saorín, T. (2011). Exposiciones digitales y reutilización: aplicación del software libre Omeka para la publicación estructurada". Métodos de información (MEI), II época, 2(2), 29-46

\section{Anexo}

\section{Pais: Brasil}

Institución: Biblioteca Nacional de Brasil.

Página web:

https://www.bn.gov.br/

Sub-sitio dedicado a exposiciones digitales:

http://bndigital.bn.gov.br/exposicoes/

Exposición digital seleccionada para el análisis:

As mãos que restauram o tempo

http://bndigital.bn.gov.br/exposicoes/biblioteca-nacional-as-maos-que-restauram-o-tempo/

\section{Pais: Perú}

Institución: Biblioteca Nacional de Perú.

Página web:

https://www.bnp.gob.pe/

Sitio dedicado a exposiciones digitales:

http://bdigital.bnp.gob.pe/Bvirtual/Exposiciones;jsessionid=cd47e7195b767163169ca96741b

Exposición digital seleccionada para el análisis:

Centro de libros chinos

http://bdigital.bnp.gob.pe/bnp/catalogo_bnp/recorrido-virtual/abancay/

\section{Pais: Colombia.}

Institución: Biblioteca Nacional de Colombia.

Página web:

http://bibliotecanacional.gov.co/es-co

Sitio dedicado a exposiciones digitales:

http://bibliotecanacional.gov.co/es-co/colecciones/biblioteca-digital/exposiciones

Exposición digital seleccionada para el análisis:

La Expedición Botánica: Revelaciones del Nuevo Mundo 
http://bibliotecanacional.gov.co/es-co/colecciones/biblioteca-digital/exposiciones/Exposicion?Exposic ion=La\%20Expedici\%C3\%B3n\%20Bot\%C3\%A1 nica:\%20Revelaciones\%20del\%20Nuevo\%20Mundo

\section{Pais: Cuba.}

Institución: Biblioteca Nacional de Cuba José Martí.

Página web:

http://www.bnjm.cu/web/app.php/

Sitio dedicado a exposiciones digitales:

http://www.bnjm.cu/web/app.php/la-biblioteca/actividades/exposiciones/exposiciones-virtuales

Exposición digital seleccionada para el análisis: -.

\section{Pais: Italia.}

Institución: Biblioteca Nazionale Centrale di Roma.

Página web:

http://www.bncrm.beniculturali.it/

Sitio dedicado a exposiciones digitales:

http://www.bncrm.beniculturali.it/it/241/mostre-on-line

Exposición digital seleccionada para el análisis:

Erbe e speziali. I laboratori della salute

http://193.206.215.10/erbe/index.html

\section{País: España.}

Institución: Biblioteca Nacional de España.

Página web:

http://www.bne.es/es/Inicio/

Sitio dedicado a exposiciones digitales:

http://www.bne.es/es/Actividades/Exposiciones/Exposiciones-virtuales/

Exposición digital seleccionada para el análisis:

Cosmos

https://cloud.madgazine.com/a1317c9f234003079/?revista=247842021\&pagina $=-51004$

\section{Pais: España.}

Institución: Biblioteca de la Universidad de Sevilla.

Página web:

http://expobus.us.es/omeka/

Sitio dedicado a exposiciones digitales:

http://expobus.us.es/omeka/

Exposición digital seleccionada para el análisis:

Guadalquivir: mapas y relatos de un rio

http://expobus.us.es/omeka/exhibits/show/guadalquivir/inicio 


\section{Pais: Francia.}

Institución: Bibliothèque nationale de France.

Página web:

http://www.bnf.fr/

Sitio dedicado a exposiciones digitales:

http://expositions.bnf.fr/index.php

Exposición digital seleccionada para el análisis:

Émile Zola. Au bonheur des dames

http://livres-enrichis.bnf.fr/bonheurdesdames/\#home

\section{Pais: Alemania.}

Institución: Staatsbibliothek zu Berlín.

Página web:

https://staatsbibliothek-berlin.de/

Sitio dedicado a exposiciones digitales:

https://blog.sbb.berlin/termine/\#ausstellungen

Exposición digital seleccionada para el análisis:

Eine Bibliothek macht Geschichte

https://blog.sbb.berlin/eine-bibliothek-macht-geschichte/

\section{Pais: Irlanda.}

Institución: National Library of Ireland.

Página web:

https://www.nli.ie/en/homepage.aspx

Sitio dedicado a exposiciones digitales:

https://www.nli.ie/en/list/programme-and-events-online-exhibitions.aspx

Exposición digital seleccionada para el análisis:

The Dublin Lockout

https://www.nli.ie/lockout/

The Life and Works of William Butler Yeats

https://www.nli.ie/yeats/

\section{Pais: Inglaterra.}

Institución: The British Library.

Página web:

https://www.bl.uk/

Sitio dedicado a exposiciones digitales:

https://www.bl.uk/discover-and-learn/online-exhibitions

Exposiciones digitales seleccionada para el análisis:

Alice in Wonderland

https://www.bl.uk/alice-in-wonderland 
$A$ history of magic

https://artsandculture.google.com/project/harry-potter-a-history-of-magic

\section{Pais: Inglaterra.}

Institución: Cambridge University Library.

Página web:

http://www.lib.cam.ac.uk/

Sitio dedicado a exposiciones digitales:

https://exhibitions.lib.cam.ac.uk/

Exposición digital seleccionada para el análisis:

Revolution: the first Bolshevik Year https://exhibitions.lib.cam.ac.uk/revolutionthefirstbolshevikyear/

\section{Pais: Inglaterra.}

Institución: Bodleian Libraries University of Oxford.

Página web:

https://www.bodleian.ox.ac.uk/

Sitio dedicado a exposiciones digitales:

https://www.bodleian.ox.ac.uk/whatson/whats-on/online

Exposición digital seleccionada para el análisis:

Sappho to Suffrage in the Weston Library

https://treasures.bodleian.ox.ac.uk/

\section{Pais: Estados Unidos}

Institución: New York Public Library.

Página web:

https://www.nypl.org/

Sitio dedicado a exposiciones digitales:

https://www.nypl.org/events/online-exhibitions

Exposición digital seleccionada para el análisis:

Frankenstein. The Afterlife of Shelly's circle

http://exhibitions.nypl.org/biblion/outsiders/shelleys-ghost

\section{Pais: Estados Unidos.}

Institución: Library of Congress.

Página web:

https://www.loc.gov/

Sitio dedicado a exposiciones digitales:

https://www.loc.gov/exhibits/

Exposición digital seleccionada para el análisis:

Baseball Americana

https://www.loc.gov/exhibitions/baseball-americana/about-this-exhibition/ 
Javier Armando Planas, et al. Las bibliotecas y las muestras digitales. Un análisis de los desarr...

\section{Pais: Estados Unidos.}

Institución: Harvard University Herbaria \& Libraries

Página web:

https://huh.harvard.edu/

Sitio dedicado a exposiciones digitales:

https://huh.harvard.edu/pages/online-exhibits

Exposición digital seleccionada para el análisis:

Amanita phalloides. The Death Cap Mushroom

http://botlib.huh.harvard.edu/libraries/Amanita_exhibit/Amanita_intro.htm

\section{BY-NC-SA}

